DE DE GRUYTER OPEN
Journal of Intercultural Management

Vol. 6, No. 4, December 2014, pp. 169-179

DOI 10.2478/joim-2014-0043

Barbara Mazur*

\title{
Building diverse and inclusive organizational culture-best practices: A case study of Cisco Co.
}

\begin{abstract}
In management theory and business practice the dealing with a diverse workforce has played a leading role in recent years. In a globalizing economy companies recognized potential benefits of a multicultural workforce and tried to create more inclusive work environments. Unfortunately many of them have been disappointed with the results they achieved. The reason for this is that too little attention has been paid for the norms, values and behaviors involved. Given the fact that diversity is essentially about cultural norms and values, appropriate reflection work becomes a fundamental task to create a truly inclusive work environment where people coming out from diverse backgrounds feel respected and recognized. The paper focus on the challenge of building an inclusive diversity culture showing that a "culture of inclusion" has to be built on solid grounds. It shed light on the process of developing such a culture in CISCO corporation which serves as an example of a good practice in this respect.
\end{abstract}

Key words: good practice, corporate culture, diversity management, HRM

\section{Introduction}

One of the major challenges in today's diverse work environment is the search for the principles to form business activities and guide actors, corporations and individuals. While diversity has been a much debated topic in management theory and practice in recent years, it were initially legal aspects (the avoidance of lawsuits) and changes in the labor market demographics (increased participation of women and minorities) that made it a subject of prime importance for corporations. Nowadays there is growing awareness among managers that diversity management should go much further than just complying with existing rules or reacting to a change in labor market resources. In management literature it is argued that the challenges within competitive, dynamic, and increasingly global markets (demand-

\footnotetext{
*bmazur@pb.edu.pl
} 
ing innovation, creativity as well as flexibility) are best met by a broadened pool of experience and knowledge found in an effectively managed diverse workforce [Cox T.H., Blake S., 1991; Mazur B., 2012]. The innovative and creative potential inherent to a diverse workforce (in terms of ethnic origin, nationality, cultural background, religion, gender, age, education, lifestyle, working style, way of thinking, etc.) can be used to bridge cultural boundaries and search for original problem solutions, innovative product ideas and targeted marketing initiatives. This diversity can become a competitive advantage [Cox T.H., Blake S., 1991].

Many organizations already have diversity policies or initiatives such as training programs in place, but they often do not show the required results like the creation of an atmosphere of inclusion [Gilbert J.A., Invancevich J.M., 2000]. They cannot achieve the benefits of diversity, let alone build a culture that embraces diversity and fosters humanity. The reason for this in the selective approach to managing diversity: assimilation, that is as opposed to integration and inclusion. The assimilation approach ignores differences among employees. Women, expatriates and minorities are more or less expected to assimilate into a pre-defined and dominant corporate culture [Thomas D.A., Gabarro J.J., 1999]. Not being heard, recognized or valued, their specific knowledge and experience is not leveraged, they cannot perform to their highest potential and they experience difficulties in advancing within the organization. Such an environment neither fosters the realization of the potential for diversity nor the retention of talented people with diverse backgrounds. Diversity management has to be built on solid normative grounds, on founding principles, understood as pillars of a culture of inclusion [Pless N.M., Maak T., 2004, p.129]. Following an inclusionary approach, differences are recognized, valued and engaged. Different voices are understood as being legitimate and as opening up new perspectives; they are heard and integrated in decision making and problem solving processes; they have an active role in shaping culture and fostering creativity and innovation; and in adding value to the company's performance. In order to unleash the potential of workforce diversity, a culture of inclusion needs to be established; a culture that fosters enhanced workforce integration and brings to life latent diversity potentials; a culture that is build on clarified normative grounds and honors the differences as well as the similarities of the individual self and others. Diversity is, first and foremost, a cultural question and thus a question of norms, values, beliefs and expectations [Pless N.M., Maak T., 2004, p.129]. As such, it is an ethical question and determined by some very essential founding principles of human coexistence. Not before this is taken into consideration, acknowledged and institutionalized, can "diversity management" be successful. However diversity may have started out in a corporation - as a response to legislative mandates, as a reaction to the shortage in qualified personnel or to become more attractive for young talentsit is important to realize that diversity management will not unleash any potential 
benefits unless diversity is culturally valued [Pless N.M., Maak T., 2004, p.130].

The main purpose of the paper is to indicate, to companies operating on multicultural markets, how an inclusive corporate culture can be created. Cisco Co. is presented as an example of good practice to be benchmarked for companies with less experience in managing diversity. The basic information about Cisco Co. and its culture comes from the company's webpage. The paper consists of three parts. It starts by introducing the term of inclusive diversity culture, the concept of organizational best practices is discussed next. It finishes with the presentation of diversity and inclusion in corporate culture of Cisco Co.

\section{An inclusive diversity culture}

When talking about a culture of inclusion it is about an organizational environment that allows people with multiple backgrounds, mindsets and ways of thinking to work effectively together and to perform to their highest potential in order to achieve organizational objectives based on sound principles. In such an environment different voices are respected and heard, diverse viewpoints, perspectives and approaches are valued and every employee is encouraged to make a unique and meaningful contribution. In order to bring such a vision of inclusion to life definitions of diversity and inclusion need to be established.

Diversity and inclusion are terms frequently used together. At the first glance diversity describes the spectrum of human similarities and differences. Inclusion, on the other hand, describes the way an organization configures opportunity, interaction, communication, information and decision-making to utilize the potential of diversity. Achieving inclusion means creating the structures, policies and practices in organizational life that recognize more than one view and signal the importance of learning from differences [Mazur B., 2009, pp. 34-46]. Inclusion refers to the systemic nature of an organization. It is not necessarily limited to the way an organization deals with employees; it may refer to interactions with customers and clients, partners, vendors, suppliers, and subcontractors as well.

In response to intensifying global competition, more and more organizations are striving to create inclusive work environments that can offer dramatic improvements in productivity, quality, creativity, customer service, job satisfaction and talent retention [Cox T.H., Blake S., 1991, p.47]. Those experiencing the greatest success tend to be those that make creating and sustaining an organizational culture of inclusion a leadership priority, and establish tangible ways of holding leaders throughout the organization accountable for making quantifiable progress.companies to better understand the needs of its consumers, helping modify and create products to suit a variety of tastes. To properly manage diversity, companies need to focus on creating inclusive cultures. Building an inclusive culture takes time. Once achieved, inclusive cultures help companies handle future conflict and respond to changes in the work environment. 


\section{Defining Diversity}

Diversity has been an evolving concept. Many writers define diversity as any significant difference that distinguishes one individual from another - a description that encompasses a broad range of overt and hidden qualities. Generally, researchers organize diversity characteristics into four areas: personality (traits, skills and abilities), internal (gender, race, ethnicity, I.Q., sexual orientation), external (culture, nationality, religion, marital or parental status), and organizational (position, department, union/non-union) [Johnson J.P., 2003; Simmons-Welburn J., 1999]. The trend in defining diversity seems to favor a broad definition, one that goes beyond the visible differences. One of the first researchers to use this inclusive definition, R. Roosevelt Thomas, Jr., was pivotal in moving diversity thinking beyond narrow categories. He argued that to manage diversity successfully, organizations must recognize that race and gender are only two of many diversity factors. Managers and leaders must expand their perspective on diversity to include a variety of other dimensions [Thomas R.R., 1992, p. xv]. Workplace diversity management, in his model, is also inclusive, defined as a "comprehensive managerial process for developing an environment that works for all employees" [Thomas R.R., 1992, p.10]. This general definition also enables all staff to feel included rather than excluded, permitting them to connect and fortify relationships that enable employees to deal with more potentially volatile issues that may later arise.

\section{Defining Inclusion}

Inclusion is a component of a company's culture. This allows companies to attract a wider range of qualified employees, as today's job seekers increasingly base employment decisions on a company's culture and reputation. The light should be sheds on the real challenge of inclusion, stating it's to find common cause for important work. This can't be done effectively if employees isolate themselves from each another based on differences such as race, culture, nationality, gender, ability, and personality. Inclusion doesn't mean an employee has to like everyone they work with, but they must still respect the opinions of fellow employees. Allowing companies to quiet cultural discord inclusion is a set of policies, procedures, programs, set of norms, and actions that create an environment where the people who make up this diversity are able to use their difference to a company's benefit, not to its detriment.

\section{Managing diversity and inclusion best practices}

Best practices are defined as practices which are most appropriate under the circumstances, especially as considered acceptable or regulated in business; techniques or methodologies that, through experience and research, have reliably led to desired or optimum results. Part of the challenge in identifying best practices in diversity management is that the field lacks empirical research assessing particular 
diversity practices to determine if they will produce 'desired or optimum' results [Coats R., Goodwin J., Bangs P., 2000; Pitts D., 2006]. Most writing is descriptive. Two core resources for workplace diversity best practices are Aronson's [2002] article on Managing the diversity revolution: Best practices for 21st century business and the U.S. G.A.O.'s [2005] report on Diversity management: Expert-identified leading practices and agency examples. Aronson gives an overview of workplace diversity, outlining how to institute a diversity initiative, summarizing the principles on which it should be based, and providing a substantial number of best practices examples implemented by various companies. The GAO's review included a comprehensive literature review, a detailed analysis of the writings of five diversity experts, and interviews with an additional 14 experts. From this process, they identified nine best practices. According to P. Kreitz the two works compliment each other. Aronson's business perspective and wealth of best practices detail is balanced by the GAO's non-profit agency examples and its high-level focus on diversity principles [Kreitz P., 2007, p.4].

The GAO's nine leading best practices are:

1. Top leadership commitment - a vision of diversity demonstrated and communicated throughout an organization by top-level management.

2. Diversity as part of an organization's strategic plan - a diversity strategy and plan that are developed and aligned with the organization's strategic plan.

3. Diversity linked to performance - the understanding that a more diverse and inclusive work environment can yield greater productivity and help improve individual and organizational performance.

4. Measurement - a set of quantitative and qualitative measures of the impact of various aspects of an overall diversity program.

5. Accountability - the means to ensure that leaders are responsible for diversity by linking their performance assessment and compensation to the progress of diversity initiatives.

6. Succession planning - an ongoing, strategic process for identifying and developing a diverse pool of talent for an organization's potential future leaders.

7. Recruitment - the process of attracting a supply of qualified, diverse applicants for employment.

8. Diversity training - organizational efforts to inform and educate management and staff about diversity's benefits to the organization [GAO 2005, p. 4].

Aronson's analysis presents top-level best practices but also drills down into more detailed and specific advice and examples of tactics, practices, and policies. He begins with the same requirement as the GAO's analysis-commitment from the top - with a similar focus on communication and demonstration which he calls concrete actions. Defining diversity as inclusiveness, he asserts that the second best practice is 'bringing people on board'. While this practice did not make the GAO's list, from many diversity experts' writings [Mor Borak M., 2005; Thomas R.R., 
1992], employee involvement is critical to building workplace diversity success. His third practice, which is implied by several of the practices the GAO identified, is assessing where an organization currently stands, that is, a diversity audit. His suggestions for how to conduct this audit match the advice given in a number of other textbooks and articles on diversity [Love J.B., 2001; Winston M.D., Li H., 2000]. The fourth, and the most detailed, best practice mirrors the GAO's second practice. An organization must develop a strategic plan to promote diversity and Aronson's includes six critical elements:

- A compelling analysis of the business case identifying diversity's advantage(s) for the organization.

- Recommendations for involving all employees in the diversity effort.

- Institutionalization of the diversity initiative through an office or individual responsible for the strategic plan at the executive level.

- Clearly defined goals tied to the gaps found through the diversity audit and the business goals.

- Diversity metrics to track progress toward those goals.

- Accountability metrics which hold managers responsible for meeting diversity goals [Aronson D., 2002, pp. 16-18].

After discussing these four best practices, Aronson describes in detail many policies, processes, and tactics used to incorporate diversity into an organization. He categorizes these more specific best practices into five areas: recruitment and hiring, promotion and career advancement, alternative dispute resolution, management accountability, and human factors. In each section, he provides numerous examples of successful implementation tactics to support that best practice. At the end of his article, Aronson includes a best practices cheat sheet comprised of 46 one- to two-line suggestions for successfully implementing a diversity initiative. Let's add to Aronson's list another example of successfully implemented diversity in the workplace.

\section{Diversity and inclusion as a Good Practice in CISCO Corporation}

Cisco slogan reads: culture employees ... are our competitive advantage

Sandy Hoffman, Cisco Chief Diversity Officer, declares: "We believe that inclusion and diversity is key to redefining how we collaborate, connect, communicate, and work. When embraced, I and D can fuel our innovation engine and help redefine our culture moving forward".

Cisco co. operates in 165 countries worldwide. It engages more than 74,000 workers, out of which 28,000 (39\%) are engineers, and utilizes 170 labs around the world. It has nearly 70,000 channel partners and holds more than 17,000 patents. The company has executed nearly 170 acquisitions since 1993. The broad portfolio of Cisco's integrated products and solutions places it either at the market leader or 
challenger position in most market segments it serves. The vision of the company is to help to change the way the world works, lives, plays, and learns. It's strategy focuses on solving customers' most important business challenges by delivering intelligent networks and technology architectures built on integrated products, services, and software platforms.

Incorporated in 1984, Cisco had a culture based on the principles of customer focus, transparent communication, employee empowerment, integrity, and frugality. Therefore for Cisco, building an inclusive and diverse organization is an ongoing and essential business imperative. The company's management believes it is their responsibility to:

- Empower their teams

- Eliminate biases

- Create an environment where everyone feels welcomed, valued, respected, and heard.

By partnering with their business leaders, human resource organizations, and key stakeholders and constituents, the company has built a holistic diversity framework. They have constructed an Inclusion and Diversity Coalition, a global team that advises and supports Cisco executives at the function and region level. Along with established inclusion and diversity ambassadors, it includes advocates in the field. The team helps to accelerate program execution by reinforcing inclusion and diversity communication and expectations.

Cisco believes that the great leaders will be those who incorporate considerations of diversity and inclusion into their habits as leaders and into the mainstream of their organizations. It moreover declares:

- Only through a culture of inclusion can we connect and serve new customers in emerging unexplored markets, reaching people, places and potential-ensuring our continued success.

- Innovation is fueled by an inclusive environment where employees are fully engaged.

- Both managers and individual contributors are measured upon creating a culture of inclusion - it is up to all of us!

- The goal for a manager is to lead across geographic and functional boundaries to include others equally; hire employees who complement and add diversity to existing teams; leverage diverse suppliers; address biased, disrespectful and/or intolerant behaviors, creating an environment where every member of the team is encouraged to voice views; demonstrate support for flexible work practices and inclusion forums.

According to Cisco, the ways in which the Managers should Enact the Inclusion and Diversity Goals are as follows:

- Schedule meetings at times that accommodate all geographies; make an effort to 
have face to face meetings with employees in other locations via WebEx, and/ or TelePresence.

- Hire employees who complement and add diversity to existing teams. Broaden recruitment sources rather than always recruiting from the same talent pool.

- Include diverse suppliers when using outside resources for contracted products or services.

- Avoid making judgments about people based on assumptions or personal bias. Effectively address inappropriate behavior (based on culture, race, gender, age, personality, or other differences) and intervene if observed.

- Lead by example and actively encourage others to practice inclusion. Create an environment where every member of the team is encouraged to voice their opinions and provide their contribution.

- Demonstrate support for flexible work practices. Encourage use and approve request of FWP as much as possible. Share program details with team and become familiar with options to discuss as part of development planning.

- Encourage employees to take a leadership role or participate in employee resource groups (ERGs). Participates as an Ambassador, or member of diversity/ inclusion leadership team for function/group.

- Acquire perspectives from a variety of team members to solve problems and achieve business objectives.

- Recognize and reward people based on performance, rather than association with any "favored" group or clique.

The advantages of an Inclusive and Diverse Culture, observed by the company, are the following:

- Attracting and engaging a multicultural, multigenerational, multi-talented global workforce is a must to drive new levels of creativity and collaboration which fuel innovation.

- Serving the changing needs of an increasingly diverse set of global customers requires an organization with people that can understand, relate and respond.

- Inclusion and Diversity is good for the bottom line.

The corporation names the benefits of an Inclusive and Diverse Culture for a single employee:

- It raises the value of differences as the vital source of new ideas, new thinking and innovation.

- It encourages a new level of curiosity and knowledge of others, as an essential need, to use the best in everyone.

- It enables rich communication with an openness for new thinking and advances the possibilities through technology.

- It emphasizes personal responsibility as a core value; challenging us to keep it top of mind; inspires others to do the same by our example.

- It brings people together in new and different combinations to collaborate 
and promote innovation, new technology, new business models and new opportunities to grow.

- It makes Cisco a great place to work.

\section{The Next Steps to be taken by Cisco employees read as follows:}

- Identify the two or three areas that you focused on which contributed to an inclusive and diverse culture.

- Record the specific actions you took and the results achieved.

Before taken them the self-assessment tool which is a part of the "Inclusion \& Diversity" section in Cisco's "Performance Review" should be introduced. The questionnaire is to be filled out individually and for personal use only. The tool's aim is to indicate respondent's proximity to fulfilling Cisco's goals of the 'Individual Contributor". Amongst the goals to be accomplished, one can name the following: an Individual Contributor is not oblivious to intolerant behaviors, includes others equally in the workplace and participates actively in inclusion forums.

- The respondent is to rate nine statements with regards to the frequency of his/ her personal behavior. A scale of 1 to 5 is presented, where 1 indicates 'rarely', 5 indicates "always" and numbers 2, 3 and 4 indicate the intensity of "sometimes". The statements concern the following issues: recognizing culture, time zone and generational differences in order to include others in the work, taking action when witnessing a disrespectful or hurtful situation towards others in the workplace, actively socializing with people from varied backgrounds, seeking numerous perspectives from different specialists in order to accomplish the business goals most innovatively, listening to opinions of others respectfully, accepting different viewpoints and showing that every opinion is meaningful, participating in an Employee Resource Group and Cisco's Inclusion and Diversity program. After answering the questionnaire, the respondent is asked to count his/ her score and see whether his/her personal expectations have been met.

Cisco co. claims it is "up to you" to:

- Promote a culture of inclusion, trust, and mutual respect - guarantee that everyone who does business with you, or who works with you, will experience a culture of inclusion, trust, and mutual respect. Tolerate nothing less.

- Lead by example every day - appreciate differences. Model inclusiveness more by your actions than your words. As Gandhi said, „Be the change you want to see in the world".

- Integrate diversity and inclusion considerations into your mainstream business - procedures, practices, programs, and behavior. Consider who you invite into your inner circle, who you talk with, spend time with, and get to know. 


\section{Conclusions}

When measured over the last ten years, companies with strong inclusion and diversity initiatives had a $23.5 \%$ higher shareholder return than others. Today's organizations face increasing demands for responsiveness, adaptability, innovation, speed, and responsible corporate citizenship. No organization can afford to dismiss the potential benefits of having a diverse and inclusive culture. Organizations wishing to become more inclusive to cultural diversity may choose to examine all their organizational policies and practices to ensure that not only are they not discriminatory but the systems and values actually contribute to making an inclusive and welcoming organizational culture. It is not enough to add new ways of working, if we do not remove old systems that reinforce the exclusionary practices nor surface the values that underlie them. We must be sure to address these underlying systemic and cultural factors.

The model of corporate culture founded on diversity and inclusion, as exemplified by Cisco Co., has a significant impact on further development of human relations school in management. Although the presentation of good practices in creating inclusive culture was limited to a single company, it can be assumed that Cisco Co. is the leader in creating good practices. The establishing of inclusive corporate culture is a process which needs to be managed. Further research could discover who is involved in this process and what its stages are. Implications of the presented good practice in establishing inclusive culture in organizations are limited mainly to a number of companies which would like to follow the example of Cisco Co.

\section{Bibliography}

Aronson D. (2002) „Managing the diversity revolution: Best practices for 21st century Business" Civil Rights Journal, no.6, pp.46-66.

Coats R., Goodwin J., Bangs P. (2000) „Seeking the best path: Assessing a library's diversity climate" Library Administration \& Management, no.14, pp.148-154.

Cox T. H., Blake S. (1991) „Managing Cultural Diversity: Impactions for Organizational Competitiveness" Academy of Management Executive 5(3), pp. 45-56.

Gilbert J. A., Ivancevich J.M. (2000) „Valuing Diversity: A Tale of Two Organizations”, Academy of Management Executive 14(1), pp. 93-105.

Johnson J.P. (2003) Creating a diverse workforce, Retrieved February 13. 2007, from http:// www.shrm.org/hrresources/whitepapers_published/CMS_005379.asp\#P-4_0.

Kreitz P. A. (2007) Best Practices for Managing Organizational Diversity, SLAC-PUB-12499 May, 2007.

Love J.B. (2001) „The assessment of diversity initiatives in academic libraries” Journal of Library Administration, no. 33, pp. 73-103.

Mazur B. (2012) Kultura organizacyjna w z̧óżnicowanym wyz̨aniowo otocz̧eniu, Białystok: Oficyna Wydawnicza Politechniki Białostockiej. 
Mazur B. (2009) Zarzqdzanie w warunkach różnorodności zasobów lud₹̨ich, Białystok: WSFiZ.

Mor Borak M. (2005) Managing diversity: Toward a globally inclusive workplace, Thousand Oaks, CA: Sage Publications.

Pitts D.W. (2006) „Modeling the impact of diversity management” Review of Public Personnel Administration, no. 26, pp. 245-268.

Pless N. M., Maak T. (2004) „Building an Inclusive Diversity Culture: Principles, Processes and Practice" Journal of Business Ethics, no. 54, pp. 129-147.

Simmons-Welburn J. (1999) „Diversity dialogue groups: A model for enhancing work place diversity" Journal of Library Administration, no. 27, pp. 111-121.

Thomas D. A., Gabarro J.J. (1999) Breaking Through: The Making of Minority Executives in Corporate America, Harvard Business School Press, Boston: Harvard Business School Press.

Thomas R.R., Jr. (1992) Beyond race and gender: Unleashing the power of your total work force by managing diversity, New York: AMACOM.

U.S. Government Accountability Office (2005) Diversity management: Expert identified leading practices and agency examples, GAO-05-90. Washington, D.C.: G.A.O. Online report available at http://www.gao.gov/new.items/d0590.pdf.

Winston M.D., Li H. (2000) „Managing diversity in liberal arts colleges” College \& Research Libraries, no. 61, pp. 205-215.

http://wmw.slideshare.net/amrithasiddharth/ciscos-organization-culture-15830432. 